\title{
BMJ Open Living with chronic migraine: a qualitative study on female patients' perspectives from a specialised headache clinic in Spain
}

\author{
Domingo Palacios-Ceña, ${ }^{1}$ Beatriz Neira-Martín, ${ }^{2}$ Lorenzo Silva-Hernández, ${ }^{2}$ \\ Diego Mayo-Canalejo, ${ }^{2}$ Lidiane Lima Florencio, ${ }^{3}$ César Fernández-de-las-Peñas, ${ }^{1}$ \\ Héctor García-Moreno, ${ }^{2}$ David García-Azorín,, ${ }^{2}$ María Luz Cuadrado ${ }^{2,4}$
}

To cite: Palacios-Ceña D, NeiraMartín B, Silva-Hernández L, et al. Living with chronic migraine: a qualitative study on female patients' perspectives from a specialised headache clinic in Spain. BMJ Open 2017;7:e017851. doi:10.1136/ bmjopen-2017-017851

- Prepublication history and additional material are available. To view these files please visit the journal online (http://dx.doi. org/10.1136/bmjopen-2017017851).

Received 20 May 2017 Revised 7 July 2017

Accepted 14 July 2017

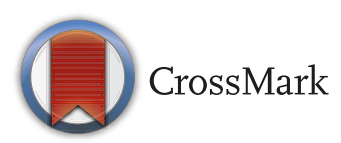

${ }^{1}$ Department of Physical Therapy, Occupational Therapy, Rehabilitation and Physical Medicine, ITPSE Research Group, Universidad Rey Juan Carlos, Alcorcón, Madrid, Spain ${ }^{2}$ Department of Neurology, Headache Clinic, Hospital Clínico San Carlos, Madrid, Spain ${ }^{3}$ Universidade de São Paulo HCFMRP-USP, Ribeirão Preto, Brazil

${ }^{4}$ Department of Medicine,

School of Medicine, Universidad Complutense de Madrid, Madrid, Spain

Correspondence to Professor María Luz Cuadrado; mlcuadrado@med.ucm.es

\section{ABSTRACT}

Objectives The aim of this study was to explore the views and experiences of a group of Spanish women suffering from chronic migraine (CM).

Setting Headache clinic at a university hospital in Madrid (Spain).

Participants Purposeful sampling of patients that attended a specialised headache clinic for the first time between June 2016 and February 2017 was performed. The patients included were females aged 18-65 and with positive diagnoses of $\mathrm{CM}$ according to the International Classification of Headache disorders (third edition, beta version), with or without medication overuse. Accordingly, 20 patients participated in the study with a mean age of 38.65 years (SD 13.85).

Design Qualitative phenomenological study.

Methods Data were collected through in-depth interviews, researchers' field notes and patients' drawings. A thematic analysis was performed following appropriate guidelines for qualitative research.

Results Five main themes describing the significance of suffering emerged: (a) the shame of suffering from an invisible condition; (b) treatment: between need, scepticism and fear; (c) looking for physicians' support and sincerity and fighting misconceptions; (d) limiting the impact on daily life through self-control; and (e) family and work: between understanding and disbelief. The disease is experienced as an invisible process, and the journey to diagnosis can be a long and tortuous one. Drug prescription by the physician is greeted with distrust and scepticism. Patients expect sincerity, support and the involvement of their doctors in relation to their disease. Pain becomes the main focus of the patient's life, and it requires considerable selfcontrol. The disease has a strong impact in the work and family environment, where the patient may feel misunderstood.

Conclusions Qualitative research offers insight into the way patients with $\mathrm{CM}$ experience their disease and it may be helpful in establishing a more fruitful relationship with these patients.
Strengths and limitations of this study

- This study presents new data on the perception of chronic migraine (CM) among female patients attending a specialised headache clinic for the first time.

- In-depth interviews and descriptions of patients drawings were used to collect qualitative data as they enable the patient's experiences with chronic pain to be analysed.

- Although the results cannot be extrapolated to the entire population of patients with $\mathrm{CM}$, they can help physicians better understand the impact of the disease and the patients' perspectives.

- The findings of this study may help to improve the management of patients with $\mathrm{CM}$.

\section{INTRODUCTION}

Migraine is one of the main causes of disability worldwide, ${ }^{1}$ with a global prevalence of $12 \%{ }^{2}$ The International Classification of Headache Disorders (third edition, beta version: ICHD-3 beta) defines chronic migraine (CM) as a headache registered on more than 15 days a month, over more than 3 months, that on a minimum of 8 days each month has the typical characteristics of migraine, or responds to triptans or ergot drugs. ${ }^{3} \mathrm{CM}$ is always a progression from episodic migraine $(\mathrm{EM}),{ }^{4}$ and as the frequency of headaches increases, it is common for the clinical features of migraine to change and characteristic migraine episodes combine with other less painful episodes that resemble tensiontype headaches. In some cases, patients with CM suffer headaches of such persistence that it becomes impossible to distinguish individual episodes of pain. ${ }^{5} \mathrm{CM}$ is the most common cause of chronic daily headache, with a global prevalence between $0.5 \%$ and $5 \%,{ }^{6}$ and an estimated $2.5 \%$ of patients with 
EM progress to $\mathrm{CM}$ each year. ${ }^{7} \mathrm{CM}$ mainly affects females (with a 2.5-6.5 higher frequency than in males), and it is associated with other risk factors, such as age, time since migraine onset, overuse of analgesics or low socioeconomic status. ${ }^{7-10}$ Frequently, comorbidity exists with other disorders such as chronic pain, anxiety, depression and obesity. $^{8}$

Standardised questionnaires, such as the Headache Impact Test (HIT-6), the Migraine Disability Assessment Scale or the Short Form-36, have demonstrated that CM is more debilitating and causes a stronger reduction in quality of life than EM. ${ }^{11-13}$ Nevertheless, the true life experience and impact of the disease are extremely personal, and there are aspects that cannot be measured with scales or questionnaires. Individual perspectives and the account of pain are relevant, inasmuch as one's life experiences, aspirations and emotional needs must be considered when treating the individual. ${ }^{14}$ Qualitative research $(\mathrm{QR})$ can provide a more holistic picture that may be more meaningful to practitioners. ${ }^{15} 16$ Indeed, QR has already been used to analyse how migraine affects a patients' work, leisure, social and family life. ${ }^{17-20}$ It has also been applied to the analysis of patients' expectations of the healthcare system and different therapeutic resources, including alternative therapies, and control strategies adopted by the patients themselves. ${ }^{21-27}$ However, no qualitative study to date has focused on CM, the most debilitating form of migraine. By using qualitative methods, we aimed to answer the following research question: 'what is the lived experience of patients with CM?'. ${ }^{28}$ Thus, the purpose of this study was to explore the experiences and perspectives of a group of Spanish women suffering from CM.

\section{METHODS \\ Design}

A qualitative phenomenological study was carried out to address the experiences of Spanish women with CM. In the field of qualitative studies, phenomenology attempts to understand other people's lived experiences by using first-person narratives and other sources such as personal letters, diaries and drawings. ${ }^{29}{ }^{30}$ Moreover, phenomenological studies aim to mitigate the effects of any preconceptions (bracketing). ${ }^{31}{ }^{32}$ In our study, bracketing was achieved by carefully recording the positions taken by the researchers beforehand and by using in-depth interviews as the main data collection tool. ${ }^{28}{ }^{32}$ In this way, we sought to avoid the researcher's influence on the data and reveal the nature of the phenomenon through the patients' accounts. ${ }^{29}$ Phenomenology has proved to be useful to explore the individual meaning of chronic pain. ${ }^{30}$

\section{Research team}

Prior to the study, the position of the researchers was established according to their previous experience and their motivation. ${ }^{29}$ Nine researchers (six men and three women) participated in this study, three of whom (DPC, BNM, CFP) had experience in qualitative study designs and were not involved in clinical activity and had no prior relation with the participants. The remaining investigators (LSH, DMC, LLF, HGM, DGA, MLC) had clinical and research experience with neurological patients.

\section{Participants and sampling strategies}

Patients with CM $(n=20)$ that attended the headache clinic at the neurology department of the Hospital Clínico San Carlos (Madrid) for the first time were enrolled on the study between June and December 2016. All patients were recruited at their first visit to the clinic to ensure that none of them had experienced a significant improvement—or even a reversal to EM- at the time of the study. The interviews were scheduled in the following 2 weeks. Purposeful sampling based on the relevance to the research question and not clinical representativeness was employed, ${ }^{33}$ and sampling continued until redundant information from the data analysis was achieved. ${ }^{29}$

The subjects included in the study were females aged 18-65 years old and with a diagnosis of CM according to ICHD-3 beta, ${ }^{3}$ with or without medication overuse. The exclusion criteria included: (a) the occurrence of other headaches, primary or secondary, different to medication overuse headache; (b) other chronic pain syndromes; (c) serious systemic and/or psychiatric disorders; (d) inability to communicate in Spanish or to sign the informed written consent.

\section{Data collection}

Data were collected between June 2016 and February 2017. Based on the phenomenological design, firstperson data collection tools (in-depth interviews and drawings) and researcher's field notes were used simultaneously. ${ }^{29}$ In-depth interviews (unstructured and semistructured) were used as the main tool for data collection. With participants 1-10, the interview started with an open question: 'What is your experience with CM?'. Thereafter, the researchers listened carefully, noted the key words and topics identified in the patients' responses and used their answers to ask for and clarify the content. ${ }^{29}$ In this way, relevant information was collected from the perspective of the patients. Also, during the interviews, researchers used prompts or probes: (a) to encourage the patients to provide more detail ('Can you tell me a bit more about that?'), (b) to encourage the participant to keep talking ('Have you experienced the same thing since?'), (c) to resolve confusion (paraphrasing of something that the patient had said) and (d) to show full attention by the researcher ('That's really interesting, please tell me more'). ${ }^{29}$

A first analysis was performed on the unstructured interviews of participants 1-10. This analysis revealed some relevant topics that required further study, thus making it necessary to include a second stage of data collection. This second stage (participants 11-20) consisted of 
Table 1 Semistructured interview questionnaire

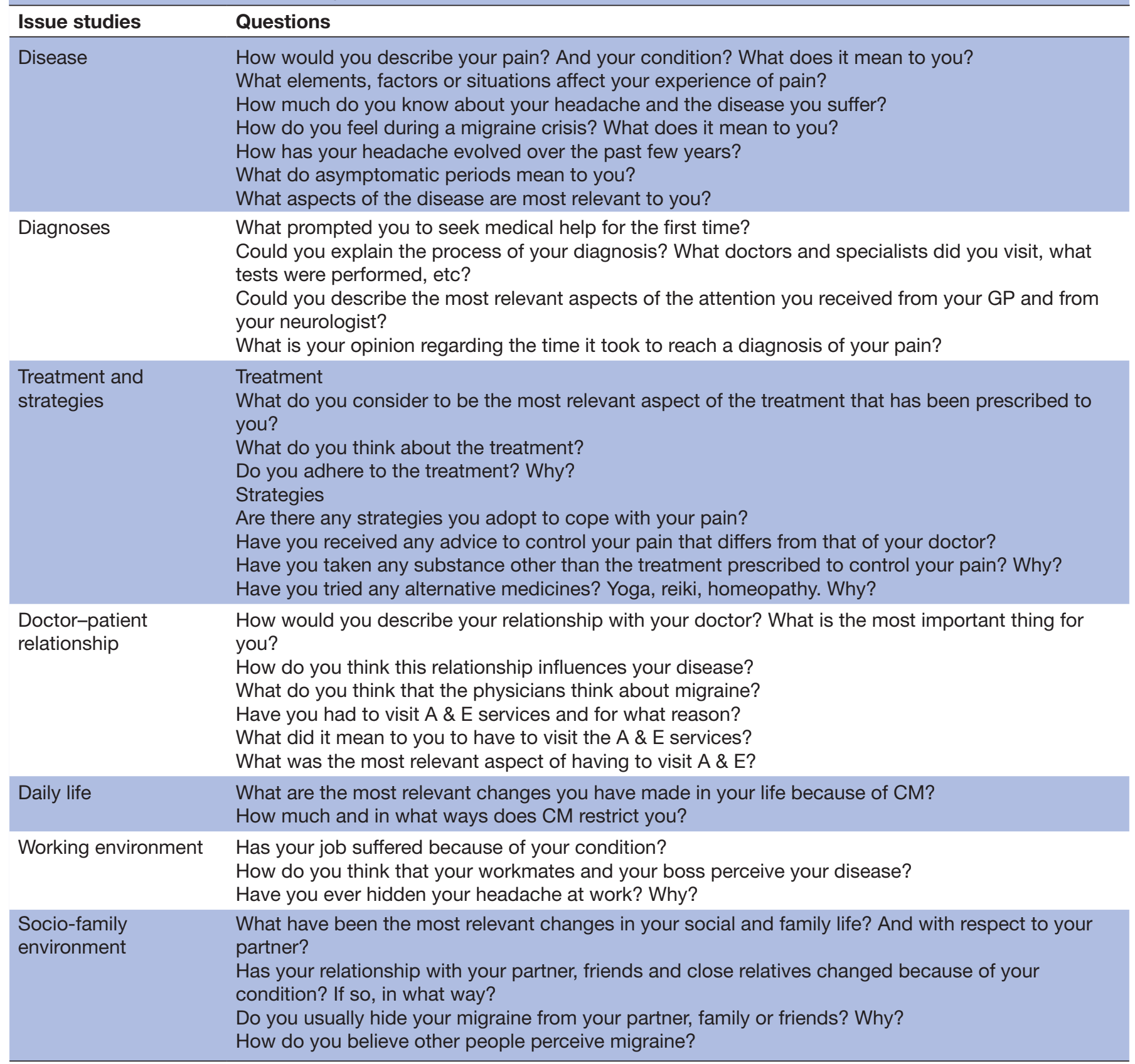

A\&E, emergency department; CM, chronic migraine; GP, general practitioner.

semistructured interviews that were based on a question guide designed to gather information regarding specific topics of interest (table 1$){ }^{29}$

All the interviews were tape-recorded and transcribed verbatim, recording $1951 \mathrm{~min}$ of interviews overall. The first 10 interviews ranged in length from 73 to $135 \mathrm{~min}$ (mean 102.9; SD 22.34), and the second set of interviews ranged from 70 to $139 \mathrm{~min}$ (mean 103.86; SD 37.61). The interviews were held at the patient's home $(n=10)$, a coffee shop $(n=3)$ or in a private room at the hospital $(\mathrm{n}=7)$, depending on the patient's preference. Interviews were carried out at a time when patients were not experiencing pain $(n=5)$ or when they suffered only mild $(n=3)$ or moderate $(\mathrm{n}=12)$ pain. None of the patients postponed their interview even when experiencing some degree of pain. No third party was present at the interviews apart from the participant being interviewed.

At the end of the interviews, the patients provided drawings that gave further insight into how they viewed their illness. ${ }^{18} 3435$ Thus, when the interview reached the point where the participant had no more new information to offer, they were asked to draw a picture of what it is like to live with CM. Participants were provided with a blank piece of paper and 24 coloured crayons for their drawing. The interview then continued with a description of the picture starting with the question: 'What does the 
picture represent?' Then researchers asked the patients to describe the content of their drawings and the reasons for their choice of colour, spatial organisation and composition. Patients' drawing descriptions and researcher field notes were part of the analysed data. Throughout data collection, these sources supported the previous ones and were often used for triangulation. ${ }^{29}$

Sociodemographic and clinical data were also recorded for each participant, as well as their Beck Depression Inventory (second edition: BDI-II) ${ }^{36}$ and State-Trait Anxiety Inventory (STAI) ${ }^{37}$ scores. In qualitative studies, the collection of sociodemographic and clinical data helps to understand patients' experiences and narrations, helps to situate them in a concrete context and serves to achieve the transferability of the results. ${ }^{29}$

The full literal transcription of each of the interviews, the patients' drawing descriptions and the researchers' field notes were all collated to perform a qualitative analysis. Finally, data collection was pursued until the researcher achieved information redundancy, at which point no new information emerged from data analysis (in our study, this occurred with patient 20). ${ }^{29}$

\section{Data analysis}

A thematic analysis was performed, which began by analysing the most descriptive content in order to arrive at meaningful units, and then went into further depth to produce thematic code groups (ie, grouping meaningful units referring to the same issue or with the same content until the main topics emerged). To identify the relevant content, researchers read and reread the data at three different levels: literally, interpretively and reflexively. ${ }^{29} \mathrm{In}$ this way, an increasing level of abstraction and complexity was established for the analysis from meaningful units to thematic code groups and finally themes. ${ }^{29}$ Each interview was analysed by two researchers, separately. After the analysis, meetings were held to show and compare the results obtained. These meetings were held with a frequency of 2 weeks, either face-to-face or by videoconference.

For clarity, a matrix was built with the results obtained from the analysis. Subsequently, joint meetings were held to combine the results of the analysis. In the case of differences in opinion, theme identification was performed based on consensus among the research team members. After that, the research team held joint meetings to show, combine and integrate the results of the analysis from each matrix. At that point, all researchers analysed and discussed the matrixes results and identified final themes by consensus among all members. ${ }^{29}{ }^{38}$ The final outcome was the identification of themes that represented the patients' experiences of suffering CM. No qualitative software was used to analyse the data. The analysis was performed by the researchers who had contact with the patients (DPC, BNM, CFP).

\section{Rigour}

The guidelines established by the Consolidated Criteria for Reporting Qualitative Research ${ }^{39}$ were followed. The data verification method consisted of: (a) cross-triangulation by the researchers, which involved planning sessions where the cases analysed by each team member were presented in order to reach a consensus; (b) auditing of the material obtained from the participants by an external independent researcher; and (c) postinterview and postanalysis patient verification. ${ }^{40}$

\section{Ethical considerations}

The study was approved by the Clinical Research Ethics Committee at the 'Hospital Clínico San Carlos' (code: 16/054-E: see technical online supplementary appendix 1 ). Informed consent and permission to record the interviews was obtained from each patient.

\section{RESULTS}

Twenty female patients with CM were enrolled on this study, and the mean age of the participants was 38.65 years (SD 13.85). Five patients had completed basic education, six secondary education and six higher education. At the time of the study, two patients were in the course of completing their university degrees and one patient was finishing her secondary education. All patients had an active lifestyle as two of them were housewives, while the remainder were either studying or working outside the home. At the time of the study, the mean time since the onset of migraine onset was of 20.2 years (SD 13.23), and the median of time since migraine had become chronic was 2 years (IQR $0.8-5$ years). In the 3 months prior to the interviews, the patients had presented a mean of 24.6 headache days per month (SD 4.7), with 12.85 days a month of moderate to intense pain (SD 6.03) and the use of symptomatic medication (paracetamol, non-steroidal anti-inflammatory drugs, triptans or opiates) on a mean of 14.1 days (SD 8.91) a month. All the patients except one had received one or more oral preventive medication, with no significant response or with an insufficient response. However, none of the patients had been treated with nerve blocks or botulinum toxin injections prior to recruitment. According to the BDI-II scores, five patients suffered mild depression and three moderate depression. Moreover, 14 patients showed some degree of anxiety as a state and 15 as a trait according to the STAI scores (see table 2 for the full demographic and clinical features of all the participants).

When the material obtained from the participants was analysed, five specific themes emerged: (a) the shame of suffering from an invisible condition; (b) treatment: between need, scepticism and fear; (c) looking for physicians' support and sincerity and fighting misconceptions; (d) limiting the impact on daily life through self-control; and (e) family and work: between understanding and disbelief. These five emerging themes were evident in the narratives taken directly from the patients' interviews and patients' drawings descriptions (see examples in table 3).

Theme 1: the shame of suffering from an invisible condition $\mathrm{CM}$ is experienced with frustration given that patients fail to achieve complete pain relief despite specialist referral 


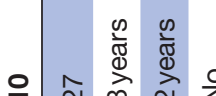

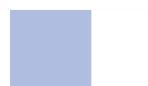

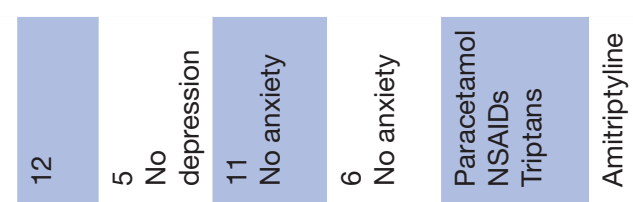

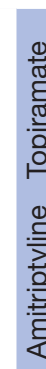

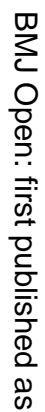

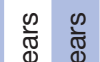

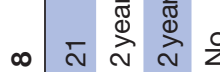

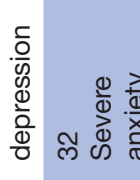

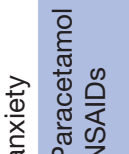

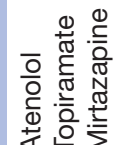

ลิ लि ले की

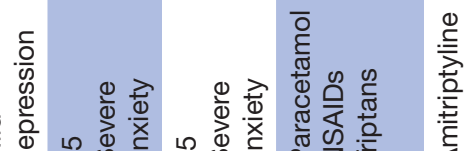

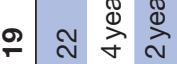

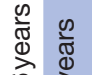

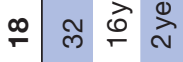

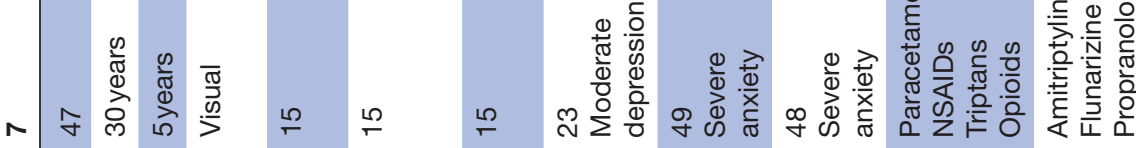

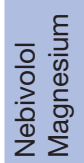

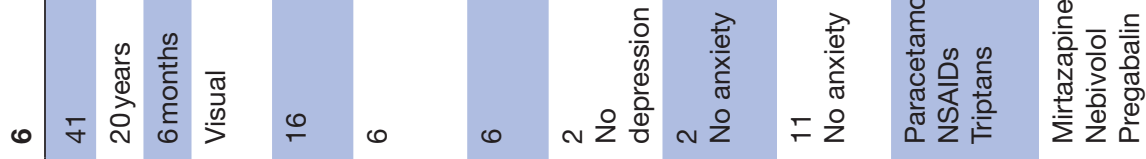

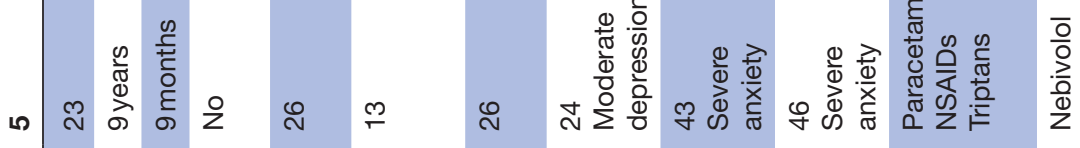

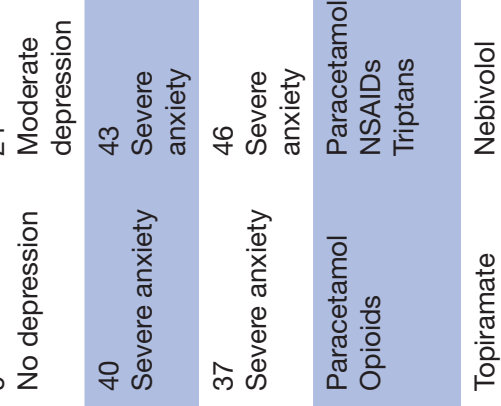

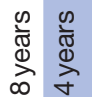

)

^ กิ

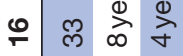

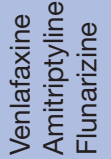

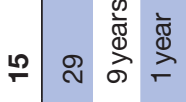

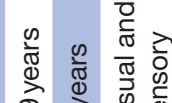

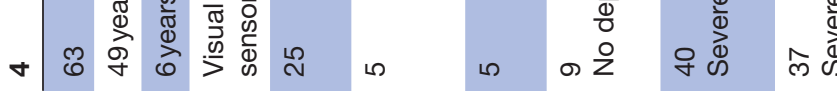

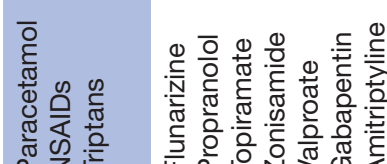

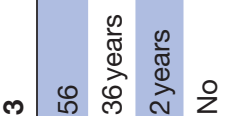

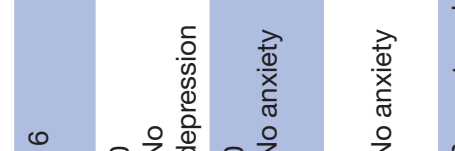

ㅇำ

离

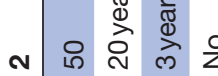

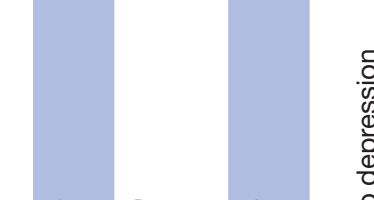

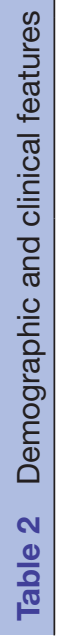

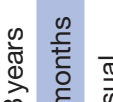

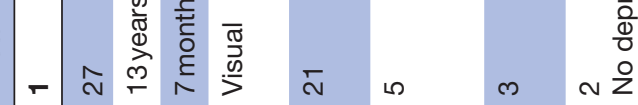

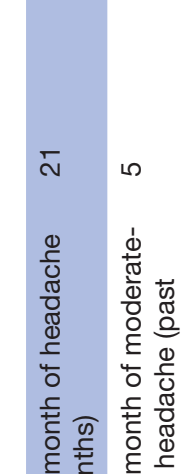

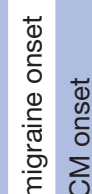

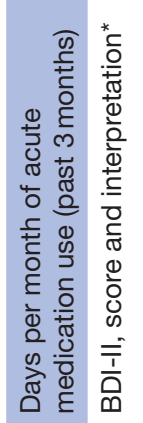

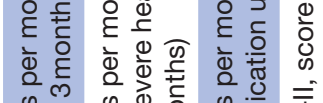

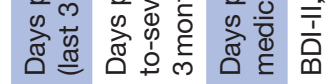
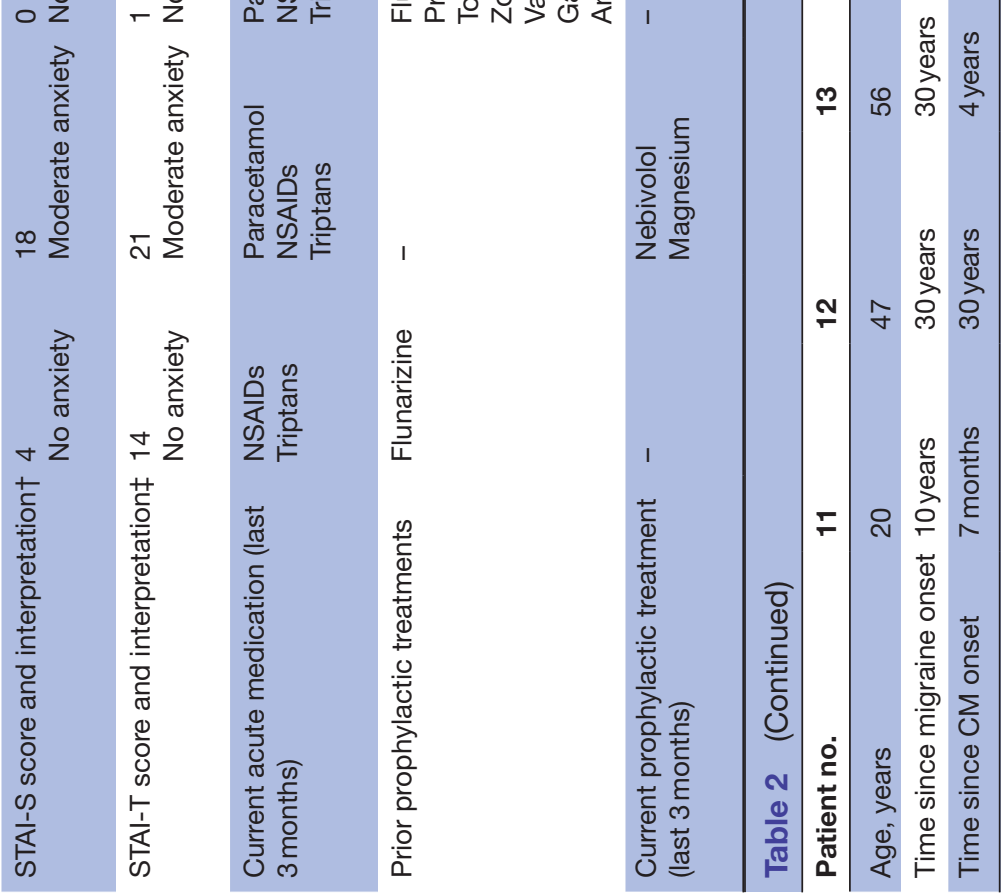

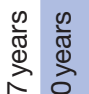

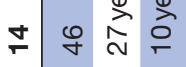

()

m

$\vec{\circ}$

Фั.

응.

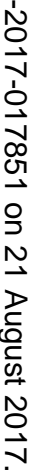

일

ㅇำ

을

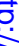

$\frac{\text { 음 }}{3}$

흠.

ญิ

옥

No

స్ 


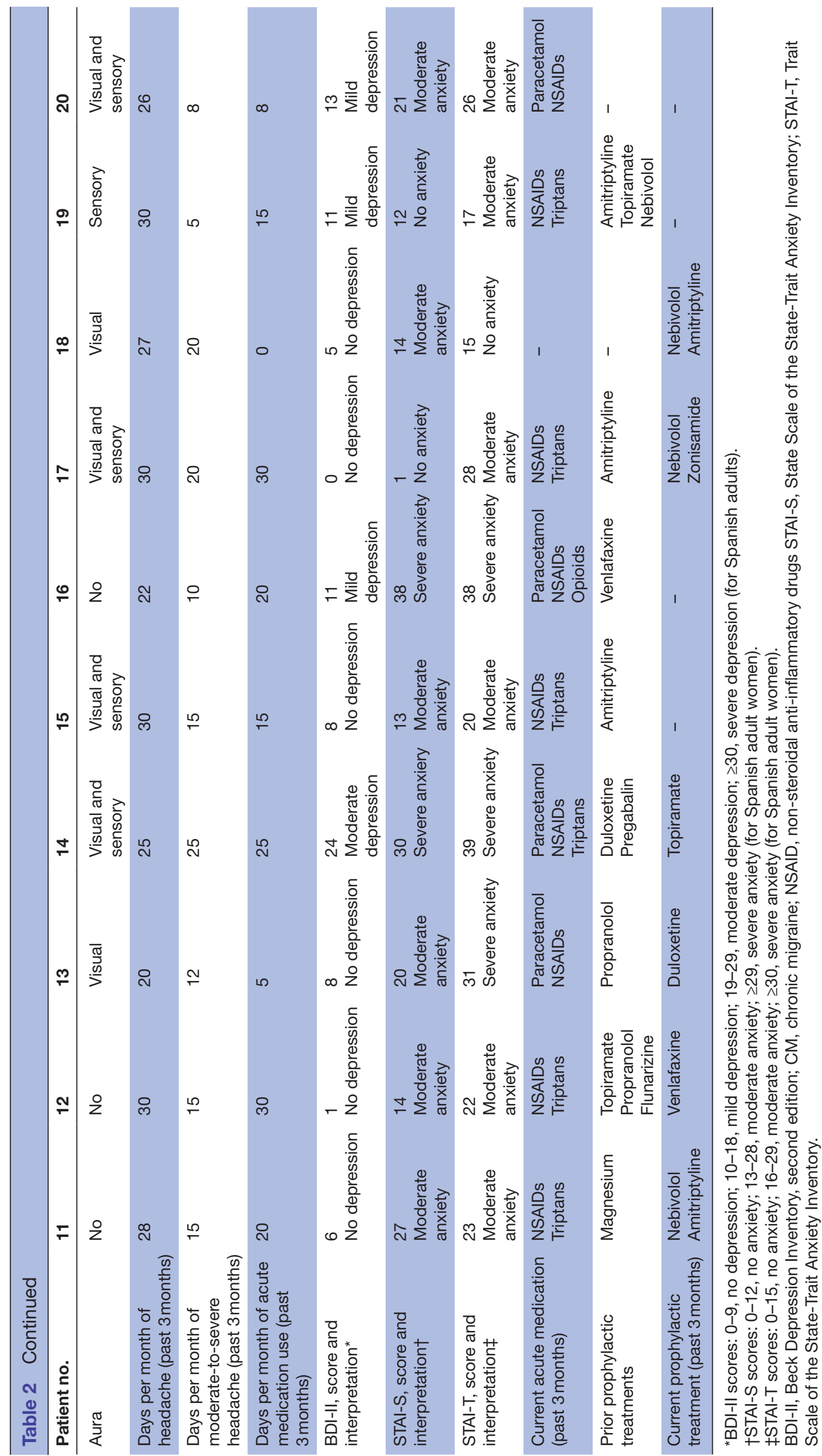




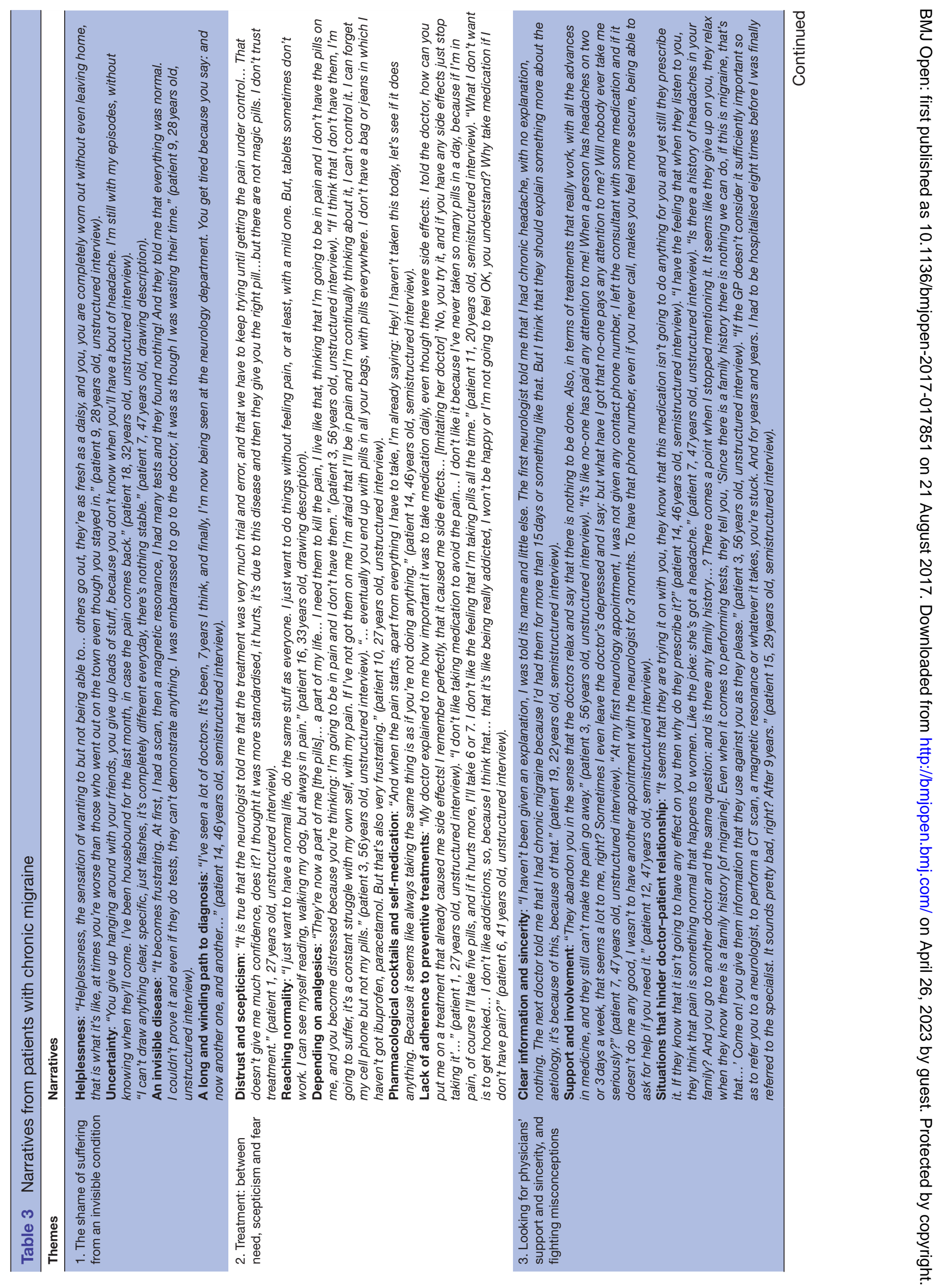




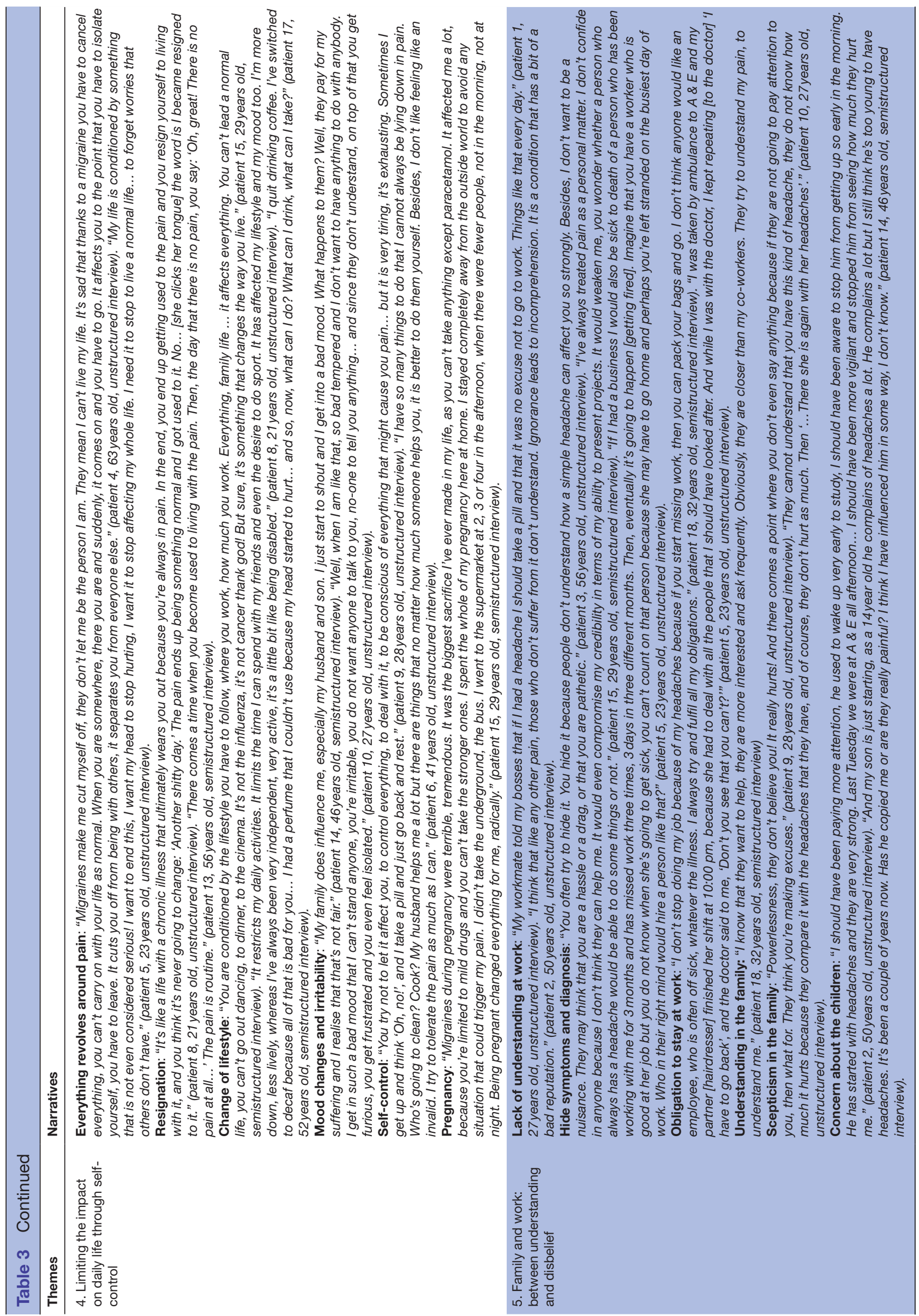


and the use of medication. All patients indicate a feeling of uncertainty when they observe how changes in their lifestyle and following standard recommendations fail to guarantee pain relief. Most of them describe CM as an invisible disease as their illness cannot be objectively demonstrated through diagnostic tests. Some patients admit feeling ashamed of seeking medical help for an invisible and little recognised disease. The arriving at a diagnosis is described as a long and tortuous process, reminiscent of an obstacle course. Many had to visit several doctors before being diagnosed with CM.

\section{Theme 2: treatment: between need, scepticism and fear}

The use of pharmacological drugs is perceived with distrust and scepticism by most patients, since acute treatment (symptomatic) does not provide complete pain relief and preventive treatment does not completely avoid pain resurgence. Patients do not believe they will become pain free and, to them, a successful treatment should reduce pain to levels that would allow them to live a 'normal' life and to get on with their lives.

Paradoxically, and despite distrust of analgesic and other symptomatic treatments, some patients recognise that they need to have analgesic medication at hand wherever they go and whatever they do. Having the medication handy reassures the patients, as they can take this medication if pain emerges. The majority of patients admitted to having at some stage taken analgesic medication that they had used before, often in a cocktail, or to self-medicating with unprescribed substances.

Long-term preventive treatments are not well accepted, and some patients do not adhere to them or they abandon them. Many patients read the patient information leaflet, and they become apprehensive about the potential short and long-term adverse effects, some of which they have even experienced in the past and reproach being prescribed the same kind of drugs anew. They are also sceptical when prescribed medication that includes antidepressants, antiepileptic or antihypertensive drugs, as they feel these are not relevant to their situation. Many patients are dubious about the effectiveness of preventive medication, and some of them abandon the treatments when they experience no reduction in pain as they are not willing to continue taking a large number of pills. Some patients also reported being afraid of becoming addicted to these treatments, as they must be taken daily, in addition to painkillers. Thus, many of them finally opt for controlling their pain with analgesics or other symptomatic treatments.

\section{Theme 3: looking for physicians' support and sincerity and fighting misconceptions}

Patients do not expect a complete cure as they have assumed their pain is chronic. Some obstacles appear between patients and doctors. However, they do expect truthful information and sincerity from their doctors regarding the prospects of treatment, the progress of the disease and its significance. Most patients prefer to be presented with real alternatives, which offer them options (and hope) of controlling or lessening the pain, and to be provided with reliable information about their disease. They also appeal for support and involvement, describing how they feel isolated when having to deal with their pain and how they need to feel the support of their doctors, whereby their disease must involve both of them.

Conversely, all patients identify situations that hinder the physician-patient relationship, such as: when a doctor prescribes a treatment that has already been tried unsuccessfully in the past, when inefficient treatments are maintained for a long time, when migraine is viewed as a minor symptom or affliction, when stereotypes about women ('they are more nervous and stressed') are used to explain the disease, when a family history of migraine is considered a limiting factor to perform exploratory tests and when referral to specialists is delayed.

Theme 4: limiting the impact on daily life through self-control Pain is a constant theme in the patients' life, everything revolves around pain. The majority of patients convey resignation at not being able to live completely pain free and they have learnt to accept that they must live with it. Nonetheless, patients attempt to change their habits for fear that they may trigger pain. This change in lifestyle is the consequence of the fact that everything revolves around pain. Moreover, those changes have an impact on the patients and on their partners and family. Many patients also suffer mood swings and irritability, which affect their relationship with partners, family and friends. For this reason, they live in a constant state of self-control. They can't allow pain to overwhelm them and rule their lives. Keeping up this demanding level of self-discipline on a daily basis can be challenging, particularly at times of higher emotional stress. Only one participant (patient 15) spoke of the impact of migraine during pregnancy, a patient who experienced anxiety in anticipation of pain as the use of painkillers was restricted.

\section{Theme 5: family and work: between understanding and disbelief}

Patients encounter a lack of understanding at work, where workmates and managers are reluctant to believe that a headache could have such a strong effect. Many of them try to hide the symptoms and diagnoses for fear of being discredited and losing their jobs. Paradoxically, the majority of patients describe how they force themselves to continue to work or to return early from sick leave despite the pain, in order to avoid overburden their colleagues.

Most patients grant that they find more understanding in their family circles than at work. However, there is a certain degree of disbelief even among family members that their pain could be so debilitating or that they are not exaggerating their pain. Some patients are worried that they might have contributed to their children suffering migraine in the future by having submitted them to stress, being unable to attend family events (celebrations, school meetings, etc), because their children might imitate their 
behaviour (staying in a dark room) or because they might have passed it on in their genes.

\section{DISCUSSION}

Our results show how pain becomes the central focus in the life of patients with CM and it demands a high level of self-control. The illness is experienced as an invisible process, and the route to a diagnosis can be long and arduous. Medication does not produce complete pain relief, and prescriptions are perceived with scepticism. It is expected that doctors will be sincere, supportive and become involved in the patient's disease. This condition has a strong impact on the patient's work and family circles, where they often feel misunderstood.

To the best of our knowledge, this is the first study to describe the experiences of patients with CM using a qualitative analysis. QR has previously been applied to analyse the impact of migraine or of 'chronic daily headache'in general—on patient's lives ${ }^{22-27}$; however, this is the first study to focus specifically on CM as defined by the ICHD-3 beta diagnostic criteria. The patient's accounts, together with sociodemographic and clinical data, were collated to provide an in-depth insight of the patients' situation. Different data collecting tools were used in order to extract more information. ${ }^{29}$ Yet this study still has some limitations concerning generalisability that limit the extrapolation of our results to the whole population with CM. Chiefly, the study was limited to women, and as such, it does not reflect the impact of CM in men, although a population in which it is much less common. Second, the study was performed on patients attending a specialised headache clinic for the first time; therefore, our findings do not extend to patients with CM who have not visited a headache clinic or specialist, and likewise, we have not analysed the experiences of patients treated or managed in a specialised headache clinic for some time. This limitation could have influenced our results since purposeful sampling could have included women who were particularly dissatisfied with prior medical care. Another issue that might have influenced the results was the fact that three of the interviews were conducted in coffee shops; although the participants chose the coffee shop as a reliable and comfortable place, the environment in this setting could have limited confidentiality. ${ }^{38}$

Our results are consistent with previous studies that reveal that migraineurs, for the most part women, experience helplessness and a lack of control over their own life. ${ }^{17182241-43}$ Acceptance of the disease as well as the uncertainty of success to calming the pain and preventing migraine attacks (by a change of lifestyle and by following medical recommendations and treatment) can be a way to regain control over the disease. ${ }^{1722}$

Migraine has already been referred to as an invisible affliction. ${ }^{18} 43$ In addition, patients with migraine are thought to construct a representation of their illness based on five dimensions: beliefs about the disease aetiology, the diagnostic label and associated symptoms, the impact of the disease, the disease duration and the existence of a cure and control. ${ }^{43}$ Flaws in any of these dimensions can lead to wrong assumptions, ${ }^{44}$ including disregarding migraine as a real disease ${ }^{39}$ or its consideration as a minor disease,${ }^{24}{ }^{25}$ consequently generating shame in patients for seeking help. ${ }^{41}$ Invisibility could account for visits to different practitioners, ${ }^{41}$ as well as underdiagnosis or delayed diagnosis. ${ }^{45} 46$

Our results show that while patients are wary of the treatments prescribed to them, they take the medication to control the impact of CM on their lives. Patients with migraine and chronic daily headache have previously been said to distrust treatments, ${ }^{18} 22$ based on the failure to achieve complete pain control or to prevent further episodes. ${ }^{15} 1841$ It has also been shown how patients take medication in order to feel safer and to feel that they are regaining control of their life. ${ }^{17} 182244$ The patients' low expectations and fear of side effects justify why headache sufferers find using acute medications more acceptable than using prophylactic drugs on a daily basis. ${ }^{25}$ Radat $e t$ $a t^{43}$ showed that migraine is perceived as successive crises but not as a progressive disease, which can explain why some patients resent long-term treatments that must be taken continuously without immediate effect.

Doctor-patient relationships are of paramount importance in order to actively engage the patient in taking control of the disease and adhering to treatments. ${ }^{25}$ Our patients expect their doctor to become involved in their disease, consistent with previous studies that also found that the relationship between doctors and patients must be based on sincerity, honesty, communication and understanding of the patient's experience, prioritising this over achieving symptom remission. ${ }^{47} 48$ Previous studies reported that patients with chronic daily headache are more satisfied with doctor consultations when management is shaped to their needs and when they feel that they are listened to and their concerns are understood. ${ }^{22} 2543$ Rutberg and Öhrling, ${ }^{18}$ and Varkey et $a l^{22}$ showed that patients commonly feel that they are not taken seriously, a sense of not being believed or that the physicians lack knowledge about migraine prevention. Previous studies also document a prevailing general belief that migraine is a 'women's disorder', which exacerbates gender bias in seeking help and diagnosis. ${ }^{49} 50$

As occurred in our patients, pain has previously been described as the centre of everything, having an impact on all dimensions of the patient's life, their family and social relationships. ${ }^{24} 4143$ Patients' perceptions of the impact of their disease vary depending on the patients' commitments (work and family), their belief in their ability to cope and their ability to fit their lives around their headaches. ${ }^{22}{ }^{24}$ Our results also agree with previous studies that described an attitude of resignation and withdrawal from activities, ${ }^{22} 414344$ as well as mood swings, irritability and aggression that hinder personal relationships and work. ${ }^{843}$ Pain management may require a high degree of self-control, vigilance and constant involvement, all of which can affect the patient's quality of life. ${ }^{17184151}$ As 
previous studies show, ${ }^{17} 1841$ patients with migraine have a choice between strict compliance with recommendations (increasing the probability of avoiding pain, although involving more stress and life restrictions) and a more permissive approach, accepting that it won't be possible to control all the factors that potentially trigger pain (with less life restrictions but a higher risk of pain).

Special consideration must be given to migraine during pregnancy; while pain improves for the majority of pregnant women, a small number experience a worsening of migraine particularly during the first and third trimesters. ${ }^{525}$ Whenever pain does not cease during pregnancy, the medication and/or alternative therapeutic options available to women are limited ${ }^{52}$; this was the case in one of our patients.

Our results coincide with those of other authors describing how patients experience certain disbelief when talking about their pain in social circles and often hide their disease and its symptoms. ${ }^{17182444}$ Patients with chronic headache and migraine hide their disease for fear of losing their job, due to a lack of understanding by workmates/family, and given the notion that migraine is unacceptable in society. ${ }^{18222444}$ Headache is not accepted in its full magnitude in the patient's social circles, and as such, it is regarded as an excuse to interrupt social and work obligations. ${ }^{171844}$ With regards the workplace, migraine has a considerable impact on a patients' ability and working efficiency during pain episodes, leading to changes in the workplace, and in the specific job tasks they can perform. ${ }^{18} 44$ Paradoxically, to avoid being brought into doubt, many women push themselves to continue working despite suffering a migraine attack. ${ }^{18}$

In agreement with previous studies, ${ }^{27}{ }^{44}$ our patients were worried about the potential emotional impact their disease might have on their children, as they may on occasion be unfit to attend family events, they suffer mood swings, among others. Moreover, it has previously been shown how women that suffer migraines are insecure about their ability to take care of their own children, their condition influencing the patient's self-esteem as mothers and spouses. ${ }^{44}$

In conclusion, this study provides insight on how $\mathrm{CM}$ is experienced in a group of Spanish women attending a specialised headache clinic. Our results are in line with previous data based on patients with migraine or chronic daily headache. Moreover, our findings shed light on how CM may impact the lives of patients in a similar situation and may have important implications for clinical practice. Patients need the involvement and support of their doctors and the patient-doctor relationship must be viewed as an important element in the strategy to improve the management of CM. Knowing the patients' experiences can probably contribute to a better communication between clinicians and patients and to a greater compliance with treatments. Our study also provides grounds to guide further research into quality of life of patients with CM. In particular, it will be interesting to analyse the experience of patients who have undergone specific treatments for $\mathrm{CM}$, such as botulinum toxin injections, and those who have been treated at specialised headache clinics for some time.

Contributors DPC, BNM and MLC contributed to the conception and design of the study, the analysis, the drafting of the manuscript and its final approval, and they are in agreement with all aspects of the work. LSH, DMC, LLF and CFP contributed to the data collection, analysis, the drafting of the manuscript and its final approval, and they are in agreement with all aspects of the work. HGM and DGA contributed to the data collection, analysis, the final approval of the manuscript, and they are in agreement with all aspects of the work.

Funding Allergan funded the cost of English editing as well as the publication fee of this article. Yet, they had no role in the study design, data collection or analysis. There was no funding for the research study.

Competing interests All authors have completed the International Committee of Medical Journal Editors uniform disclosure form at www.icmje.org/coi_disclosure. pdf and declare no financial relationships that could have influenced the submitted work. Allergan funded the cost of English editing as well as the publication fee of this article. Neither honoraria nor payments were made for authorship.

Patient consent The study was sanctioned by the clinical research ethics committee at the Hospital Clínico San Carlos, Madrid, Spain (code: 16/054-E). Informed consent was obtained from all subjects prior to their participation in the study.

Ethics approval Clinical Research Ethics Committee at the Hospital Clínico San Carlos, Madrid, Spain. Technical appendix 1. Clinical Research Ethics Committee at Hospital Clínico San Carlos permission (code: 16/054-E).

Provenance and peer review Not commissioned; externally peer reviewed.

Data sharing statement There are ethical and legal restrictions in providing access to the full interviews.

Open Access This is an Open Access article distributed in accordance with the Creative Commons Attribution Non Commercial (CC BY-NC 4.0) license, which permits others to distribute, remix, adapt, build upon this work non-commercially, and license their derivative works on different terms, provided the original work is properly cited and the use is non-commercial. See: http://creativecommons.org/ licenses/by-nc/4.0/

(c) Article author(s) (or their employer(s) unless otherwise stated in the text of the article) 2017. All rights reserved. No commercial use is permitted unless otherwise expressly granted.

\section{REFERENCES}

1. Steiner TJ, Stovner LJ, Vos T. GBD 2015: migraine is the third cause of disability in under 50s. J Headache Pain 2016;17:104.

2. Woldeamanuel YW, Cowan RP. Migraine affects 1 in 10 people worldwide featuring recent rise: a systematic review and metaanalysis of community-based studies involving 6 million participants. J Neurol Sci 2017;372:307-15.

3. Headache Classification Committee of the International Headache Society (IHS). The International Classification of Headache Disorders, 3rd edition (beta version). Cephalalgia 2013;33:629-808.

4. Bigal ME, Lipton RB. Clinical course in migraine: conceptualizing migraine transformation. Neurology 2008;71:848-55.

5. Carod-Artal FJ. Tackling chronic migraine: current perspectives. J Pain Res 2014;7:185-94.

6. Natoli JL, Manack A, Dean B, et al. Global prevalence of chronic migraine: a systematic review. Cephalalgia 2010;30:599-609.

7. Bigal ME, Serrano D, Buse D, et al. Acute migraine medications and evolution from episodic to chronic migraine: a longitudinal population-based study. Headache 2008;48:1157-68.

8. Buse DC, Manack A, Serrano D, et al. Sociodemographic and comorbidity profiles of chronic migraine and episodic migraine sufferers. J Neurol Neurosurg Psychiatry 2010;81:428-32.

9. Buse DC, Manack AN, Fanning KM, et al. Chronic migraine prevalence, disability, and sociodemographic factors: results from the American Migraine Prevalence and Prevention Study. Headache 2012;52:1456-70.

10. Adams AM, Serrano D, Buse DC, et al. The impact of chronic migraine: the chronic migraine epidemiology and outcomes (CaMEO) Study methods and baseline results. Cephalalgia 2015;35:563-78. 
11. Meletiche DM, Lofland JH, Young WB. Quality-of-life differences between patients with episodic and transformed migraine. Headache 2001;41:573-8.

12. Bigal ME, Rapoport AM, Lipton RB, et al. Assessment of migraine disability using the migraine disability assessment (MIDAS) questionnaire: a comparison of chronic migraine with episodic migraine. Headache 2003;43:336-42.

13. Canuet L, Ishii R, Fernandez-Concepcion O, et al. Severity of depressive symptoms as predictor of impairment of quality of life in chronic migraine: comparison with episodic migraine. Psychiatry Clin Neurosci 2008;62:738-40.

14. Webster LR, Harden RN. Why we need narratives of healing and qualitative pain research. Pain Med 2013;14:1811-2.

15. Peters M, Abu-Saad HH, Vydelingum V, et al. Research into headache: the contribution of qualitative methods. Headache 2002;42:1051-9.

16. Coyle N, Tickoo R. Qualitative research: what this research paradigm has to offer to the understanding of pain. Pain Med 2007;8:205-6.

17. Rutberg S, Ohrling K, Kostenius C. Travelling along a road with obstacles: experiences of managing life to feel well while living with migraine. Int J Qual Stud Health Well-being 2013;8:19900-9.

18. Rutberg S, Öhrling K. Migraine-more than a headache: women's experiences of living with migraine. Disabil Rehabil 2012;34:329-36.

19. Bösner S, Hartel S, Diederich J, et al. Diagnosing headache in primary care: a qualitative study of GPs' approaches. $\mathrm{Br} J$ Gen Pract 2014;64:e532-e537.

20. Seng EK, Holroyd KA. Optimal use of acute headache medication: a qualitative examination of behaviors and barriers to their performance. Headache 2013;53:n/a-50.

21. Jonsson $P$, Jakobsson $A$, Hensing $G$, et al. Holding on to the indispensable medication - a grounded theory on medication use from the perspective of persons with medication overuse headache. $J$ Headache Pain 2013;14:43.

22. Varkey E, Linde M, Henoch I. "It's a balance between letting it influence life completely and not letting it influence life at all" - a qualitative study of migraine prevention from patients' perspective. Disabil Rehabil 2013;35:835-44.

23. Moloney MF, Strickland OL, DeRossett SE, et al. The experiences of midlife women with migraines. J Nurs Scholarsh 2006;38:278-85.

24. Peters M, Huijer Abu-Saad H, Vydelingum V, et al. The patients perceptions of migraine and chronic daily headache: a qualitative study. J Headache Pain 2005;6:40-7.

25. Peters $\mathrm{M}$, Abu-Saad HH, Vydelingum V, et al. Migraine and chronic daily headache management: a qualitative study of patients' perceptions. Scand J Caring Sci 2004;18:294-303.

26. Peters M, Abu-Saad HH, Vydelingum V, et al. Patients' decisionmaking for migraine and chronic daily headache management. A Qualitative Study. Cephalalgia 2003;23:833-41.

27. Cottrell CK, Drew JB, Waller SE, et al. Perceptions and needs of patients with migraine: a focus group study. J Fam Pract 2002;51:142-7.

28. Norlyk A, Harder I. What makes a phenomenological study phenomenological? An analysis of peer-reviewed empirical nursing studies. Qual Health Res 2010;20:420-31.

29. Carpenter C, Suto M. Qualitative research for occupational and physical therapists: a practical guide. Black-Well Publishing: Oxford, 2008.
30. Ojala T, Häkkinen A, Karppinen J, et al. Chronic pain affects the whole person-a phenomenological study. Disabil Rehabil 2015;37:363-71.

31. Dowling M. From Husserl to van Manen. A review of different phenomenological approaches. Int J Nurs Stud 2007;44:131-42.

32. Gearing RE. Bracketing in research: a typology. Qual Health Res 2004:14:1429-52.

33. Teddlie C, Yu F. Mixed method sampling: a typology with examples. $J$ Mix Methods Res 2007;1:77-100.

34. Broadbent E, Niederhoffer K, Hague T, et al. Headache sufferers' drawings reflect distress, disability and illness perceptions. $J$ Psychosom Res 2009;66:465-70.

35. Guillemin M. Understanding illness: using drawings as a research method. Qual Health Res 2004;14:272-89.

36. Maizels M, Smitherman TA, Penzien DB. A review of screening tools for psychiatric comorbidity in headache patients. Headache 2006;46(s3):S98-S109.

37. Lampl C, Thomas H, Tassorelli C, et al. Headache, depression and anxiety: associations in the Eurolight project. $J$ Headache Pain 2016;17:59.

38. Miles HB, Huberman AM, Saldaña J. Qualitative data analysis: a methods sourcebook. 3rd edn. Thousand Oaks, California: Sage, 2014.

39. Tong A, Sainsbury P, Craig J. Consolidated criteria for reporting qualitative research (COREQ): a 32-item checklist for interviews and focus groups. Int J Qual Health Care 2007;19:349-57.

40. Cohen DJ, Crabtree BF. Evaluative criteria for qualitative research in health care: controversies and recommendations. Ann Fam Med 2008;6:331-9.

41. Del Monaco R. [Self-care, adherence and uncertainty: biomedical treatments and patients' experiences regarding chronic migraine pain]. Salud Colect 2013;9:65-78.

42. Abu Bakar N, Tanprawate S, Lambru G, et al. Quality of life in primary headache disorders: a review. Cephalalgia 2016;36:67-91.

43. Radat F, Koleck M, Foucaud J, et al. Illness perception of migraineurs from the general population. Psychol Health 2013;28:384-98.

44. Ruiz de Velasco I, González N, Etxeberria Y, et al. Quality of life in migraine patients: a qualitative study. Cephalalgia 2003;23:892-900.

45. Moriarty M, Mallick-Searle T. Diagnosis and treatment for chronic migraine. Nurse Pract 2016;41:18-32.

46. Dodick DW, Loder EW, Manack Adams A, et al. Assessing barriers to chronic migraine consultation, diagnosis, and treatment: results from the Chronic Migraine Epidemiology and Outcomes (CaMEO) Study. Headache 2016;56:821-34.

47. Ozawa S, Sripad P. How do you measure trust in the health system? A systematic review of the literature. Soc Sci Med 2013;91:10-14.

48. Spence D. What happened to the doctor-patient relationship? BMJ 2012;344:e4349.

49. Kempner J. Gendering the migraine market: do representations of illness matter? Soc Sci Med 2006;63:1986-97.

50. Becker WJ, Findlay T, Moga C, et al. Guideline for primary care management of headache in adults. Can Fam Physician 2015;61:670-9.

51. Meyer GA. The art of watching out: vigilance in women who have migraine headaches. Qual Health Res 2002;12:1220-34.

52. Wells RE, Turner DP, Lee M, et al. Managing migraine during pregnancy and lactation. Curr Neurol Neurosci Rep 2016;16:40.

53. Sacco S, Ripa P. Migraine in pregnancy. J Headache Pain 2015;16:A24. 